\title{
Research on the Sealing Detection Technology for No Leak Detection Interface Specimen
}

\author{
Yingjun Huang ${ }^{a}$, Xudong Liao ${ }^{b}$, Guoyun Baic $^{\mathrm{c}}$, Tao Chen ${ }^{\mathrm{d}}$, Miao Lou ${ }^{\mathrm{e}}$ \\ The North-West Institute of Nuclear Technology, Xi'an 710024, China \\ ahuangjun888500@163.com, b511851318@qq.com, cbaiguoyun2010@sohu.com, dshuishou205@ \\ 163.com, 'Toumiao531@yahoo.com.cn,
}

Keywords: no leak detection interface; sealing property; detection technology.

\begin{abstract}
The sealing detection technology for no leak detection interface specimen was introduced, such as bubbles leak detection, back pressure leak detection, advance helium leak detection, fluorescence permeation leak detection and inside helium source leak detection, including their principles and specialties. The suitable object, advantages and disadvantages of those leak detection technologies were analyzed, which offered theory reference for doing correlative work.
\end{abstract}

\section{Introduction}

Sealing performance is the most important reliability evaluation index of vacuum equipment and pressure equipment. It is dangerous for the person and equipment when the equipment leakage happened. Therefore, it is important to research the sealing detection technology of different sealing methods and structure. The most used leak detection technology in china is helium mass spectrometer leak detection, differential pressure leak detection, ammonia leak detection, ultrasonic leak detection, et al.[1-4] However, these methods generally need to set the pressurized or vacuum interface to realize the leak detection, and the interface will be solder sealed. For these parts, the conventional detection method cannot detect the sealing performance, and will be the security problem. Therefore, it is significative to research the sealing detection technology for no leak detection interface specimen. According to the survey results and work experience, the paper discussed several methods, which were expected to detect the specimen with no leak detection interface, and provide a useful technical reference.

\section{Leak Detection Technologies for No Leak Detection Interface Specimen}

\subsection{Bubbles Leak Detection.}

(1) Heat Trough Bubble Leak Detection

If the specimen haven't join any leak indication gas or low boiling point liquid before the seal, which can produce differential pressure inside and outside the leak, it can be pressed in by high pressure blast technique. Than put the specimen in to the high boiling point liquid, the pressure in the specimen will increase and different from the outside pressure for the gas expansion or liquid volatilization, as shown in Fig. 1. The high boiling point liquid can't be intensely evaporated or boiled, which will affect the observation of the bubbles.

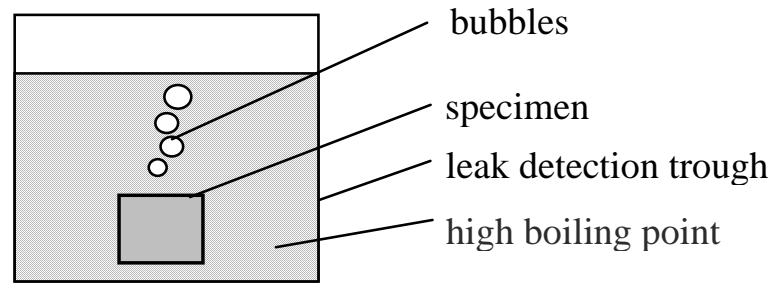

Fig. 1 The diagram of immersion bubble leak detection

(2) Vacuum Bubble Leak Detection

Like the bubble leak detection, make the leak indication gas into the specimen, and put it in the sealed container with liquid, than make the upper space into a vacuum, in order to form pressure 
difference, and the gas will discharge from the leak. The leak detection system was shown in Fig. 2.

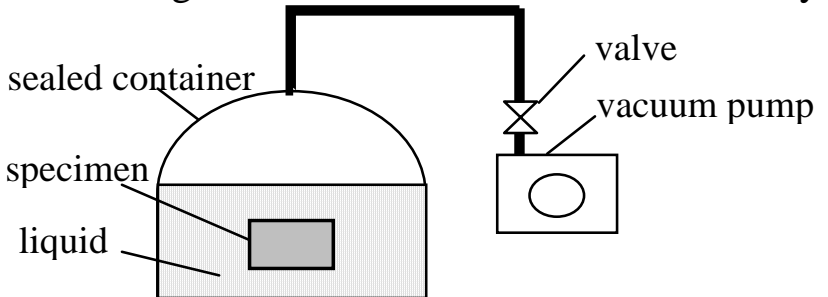

Fig 2 The diagram of vacuum bubble leak detection

The main method to estimate the leak rate is counting the number of the bubble by visual test, while this method need experienced testing personal, and the error is bigger. The concrete visual test method is: (1) If the bubble is small, uniformity and durative, the leak rate is in the range of 10-5 $10-2 \mathrm{~Pa} \cdot \mathrm{m} 3 / \mathrm{s}$; (2) If the bubble is random mixed with small and big bubble, the leak rate is in the range of $10-210-1 \mathrm{~Pa} \cdot \mathrm{m} 3 / \mathrm{s}$; (3) If the bubble is big and fast, the leak rate is in the range of $10-1 \sim$ $1 \mathrm{~Pa} \cdot \mathrm{m} 3 / \mathrm{s}[5]$.

\subsection{Back Pressure Leak Detection}

The back pressure leak detection is a common method to test the specimen with no interface, as shown in Fig. 3, it has three steps: (1) Step I is Inflating.Put the specimen into the high pressure helium container for several hours or days according to the specimen. If the specimen has leak, the He2 will be pressed into the specimen through the leak. (2) Step II is Cleansing. Release the pressure of the container, and take out the specimen. Than blow the surface of the specimen use high pressure N2 or air, or heat the specimen to some temperature to clean the He2 on the surface. While the He2 in the specimen will be lost in this process. (3)Step III is Leak Detection. Put the specimen into the vacuum container, which was connected with vacuum pump and helium mass spectrometer leak detector[6, 7]. The leak rate test by leak detector is test leak rate, called QR, and the equivalent standard leak rate is QL. The value of QR is related to the leak size and leak detection parameters. The relationship between QR and QL can be switched by formula 1[8].

$$
Q_{R}=\frac{7.23 Q_{L}^{2} p_{1} t_{1}}{V p_{0}^{2}}
$$

Where $p_{0}$ is the atmospheric pressure, $p_{1}$ is the pressure in helium container, $t_{1}$ is the pressure time, $V$ is the net volume of the specimen.

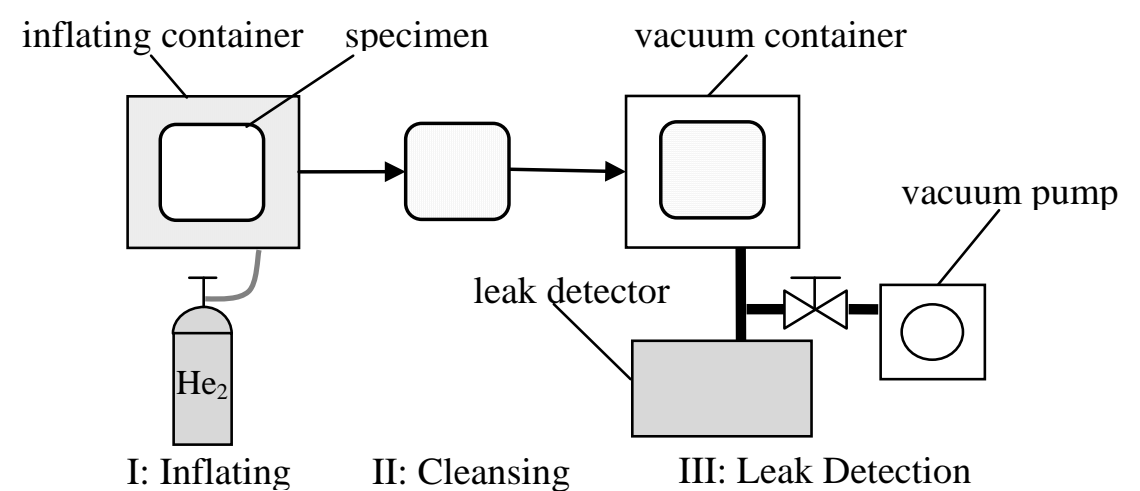

Fig 3 The diagram of back pressure leak detection

It is worth pointing out when the leak size is too big, the leak rate is bigger than $5.0 \times 10^{-6} \mathrm{~Pa} \cdot \mathrm{m}^{3} / \mathrm{s}$, the $\mathrm{He}_{2}$ in the specimen has been partly lost during the cleansing, therefore, the test result is smaller than the real leak rate. Wherefore, the specimen should be detected by rough detection after the back pressure leak detection to verify whether the specimen has big leak.

\subsection{Prefilled Helium Leak Detection}

Prefilled helium leak detection refer to fill the specimen with $\mathrm{He}_{2}$ before sealing, than detect the sealing property. Weld a KF25 connector on the specimen, vacuum it by pump use the connector, and fill it with $\mathrm{He}_{2}$ to $0.1 \mathrm{MPa}$ absolute pressure, than solder seal the connector to achieve the helium prefilling. After the helium prefilling, install a metal gas-collecting cover on the connector weld joint to connect the leak detection system, as shown in Fig. 4. It is need to point out that the leak rate show 
on the leak detector is the sum of real leak rate and system background leak rate, for the prefilled $\mathrm{He}_{2}$. Therefore, the method can only estimate the leak rate is smaller than the date on the detector as a semi-quantitative detection.

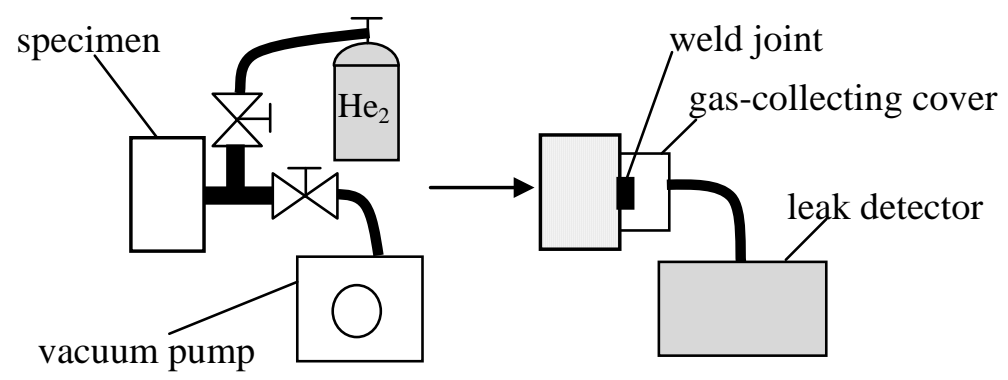

\subsection{Permeation Leak Detection}

Fig 4 The diagram of advance helium leak detection

Permeation leak detection refer to coat the specimen with penetrant contains dye, and the penetrant will seep through the penetrating defect. Permeation leak detection contains pigmentation permeation leak detection, fluorescence permeation leak detection, kerosene permeation leak detection and pressure permeation leak detection[6]. According to the structure of the specimen, there is no connector to pressurize, accordingly the pressure permeation leak detection is not suitable. Consider the high temperature of welding, kerosene and combustible pigmentation are not suitable as the penetrant. Therefore, fluorescence permeation leak detection is the best choice. About this method, the permeation should be filled into the specimen before welding sealing, than make the welding part down, the permeation will immerse the welding part and infiltrate from the defect to the external by capillarity. With the aid of dark room and UV lamp, different levels of fluorescence can be observed as shown in Fig. 5. The fluorescence permeation leak detection has the best sensitivity compare with other permeation leak detection, and the sensitivity is depending on the infiltrating time and observation method. Professor Zhu[9] of the Southwest Physics Academe in nuclear industry has found the leak of $7 \times 10^{-9} \mathrm{~Pa} \cdot \mathrm{m}^{3} / \mathrm{s}$ on the vacuum lining of focusing device by the fluorescence permeation unsaturated $\mathrm{C}_{14} \mathrm{H}_{10}$ and acetone. According to the step of this method, there are requirements for specimen's size, form and surface cleanliness, and can not show the leak rate intuitively, also the test time is longer. Meanwhile, the permeation in the specimen will erode the specimen in a certain degree, which will become a safety loophole.

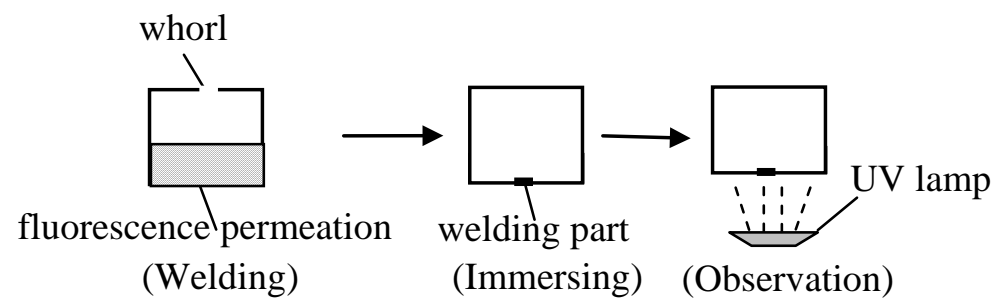

Fig 5 The diagram of fluorescence permeation leak detection

\subsection{Built-in Helium Leak Detection}

This technology was self-developed by Engineer Bai of the North-West Institute of Nuclear Technology[10]. The helium releasing device was fixed inside the specimen with cable before it was sealed, and release the $\mathrm{He}_{2}$ to $0.1 \mathrm{MPa}$ by the control device. By fixing the gas collecting cover on the sealing part and connecting the leak detector on it, the sealing performance of the sealing part can be detected as shown in Fig. 6. The size of the helium releasing device depends on the size of helium bottle, pressure and releasing concentration, specimen which size is smaller than the helium releasing device cannot use this method. If the specimen is sealed forever, the device will also be fixed in the specimen forever, therefore the device should be fixed on the safe place to prevent the device from destroying the specimen. 


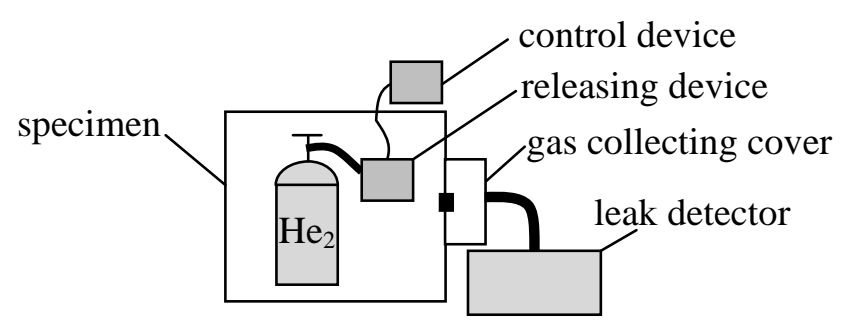

Fig 6 The diagram of built-in helium leak detection

\section{Compare the Five Kinds of Leak Detection Technologies}

Five kinds of leak detection technologies for no leak detection interface specimen has been detailedly introduced, while the applicable objects and detection effect of each method were different. By comparing the detection principle and method of each technology, the technical features of them were collected in Table 1.

As shown in Table 1, different methods have different observation method, device, sensitivity and characteristic. To the specimen with low sealing requirement, the bubbles leak detection can be simple and intuitive, meanwhile the bubbles leak detection can be the coarse detection of the high sealing requirement specimen, such as electronic component. To the specimen with high sealing requirement, if the size is small, such as electronic component, small metal, glass seals et al. the back pressure leak detection can be suitable, but the operation is complex and cannot locating the leak; if the size is big, such as vacuum or pressure container, the prefilled helium leak detection, fluorescence permeation leak detection and built-in helium leak detection can be used, while each method has the best applicable object, blindly use will not get the ideal effect, and the test result will be unreliable.

Table 1 The technical feature of different leak detection technologies

\begin{tabular}{|c|c|c|c|c|}
\hline $\begin{array}{l}\text { Detection } \\
\text { Method }\end{array}$ & $\begin{array}{l}\text { Observation } \\
\text { Method }\end{array}$ & Device & $\begin{array}{l}\text { Sensitivity } \\
\left(\mathrm{Pa} \cdot \mathrm{m}^{3} / \mathrm{s}\right)\end{array}$ & Characteristic \\
\hline $\begin{array}{l}\text { Bubbles Leak } \\
\text { Detection }\end{array}$ & $\begin{array}{l}\text { observe the } \\
\text { bubble }\end{array}$ & eye, camera & $10^{-5}$ & $\begin{array}{l}\text { depends on the experience; bigger } \\
\text { error; can't show the leak rate; low } \\
\text { demand to the structure; can orientate } \\
\text { the leak; can be used for the coarse } \\
\text { detection }\end{array}$ \\
\hline $\begin{array}{l}\text { Fluorescence } \\
\text { Permeation } \\
\text { Leak Detection }\end{array}$ & $\begin{array}{l}\text { observe the } \\
\text { fluorescence }\end{array}$ & $\begin{array}{c}\text { eye, } \\
\text { UV lamp }\end{array}$ & $10^{-9}$ & $\begin{array}{l}\text { have requirements for specimen's } \\
\text { size, form and surface cleanliness; can't } \\
\text { show the leak rate; must be upturned; } \\
\text { can orientate the leak }\end{array}$ \\
\hline $\begin{array}{l}\text { Back Pressure } \\
\text { Leak Detection }\end{array}$ & $\begin{array}{l}\text { device direct } \\
\text { show }\end{array}$ & $\begin{array}{l}\text { helium mass } \\
\text { spectrometer } \\
\text { leak detection }\end{array}$ & $10^{-12} \sim 10^{-13}$ & $\begin{array}{l}\text { high sensitivity; low efficiency; fit to } \\
\text { small leak; need coarse detection before } \\
\text { fine detection; can't orientate the leak }\end{array}$ \\
\hline $\begin{array}{l}\text { Prefilled } \\
\text { Helium Leak } \\
\text { Detection }\end{array}$ & $\begin{array}{l}\text { device direct } \\
\text { show }\end{array}$ & $\begin{array}{l}\text { helium mass } \\
\text { spectrometer } \\
\text { leak detection }\end{array}$ & $10^{-12} \sim 10^{-13}$ & $\begin{array}{l}\text { low efficiency; can't get the real leak } \\
\text { rate as a semi-quantitative detection; } \\
\text { can't orientate the leak }\end{array}$ \\
\hline $\begin{array}{l}\text { Built-in Helium } \\
\text { Leak Detection }\end{array}$ & $\begin{array}{l}\text { device direct } \\
\text { show }\end{array}$ & $\begin{array}{l}\text { helium mass } \\
\text { spectrometer } \\
\text { leak detection }\end{array}$ & $10^{-12} \sim 10^{-13}$ & $\begin{array}{l}\text { high sensitivity and reliability; easy } \\
\text { to operate; must fix the releasing device } \\
\text { in the specimen forever; have the } \\
\text { requirement to the specimen size }\end{array}$ \\
\hline
\end{tabular}

\section{Summary}

In conclusion, these five kinds of leak detection technologies for no leak detection interface specimen have different level feasibility to specific leak detection condition and object. The leak detection should be chose reasonably on the basis of specimen's characteristic. The bubble leak detection can be used for low sealing requirements specimen leak detection and coarse detection of high sealing requirements specimen; the back pressure leak detection, prefilled helium leak detection, fluorescence permeation leak detection and built-in helium leak detection can be used for high sealing requirements specimen according to their own technical feature. These conclusion can provide technical reference for the leak detection of no leak detection interface specimen. 


\section{References}

[1] Xu Hao. Seal [M]. Metallurgical Industry Press, 2005, p. 1-20.

[2] Editorial board of mechanical design handbook. Mechanical Design Handbook: Seals, Sealing and Lubrication [M]. China Machine Press, 2007, p. 3-4.

[3] Li Jiawei. Nondestructive Testing Manual(second edition) [M]. China Machine Press, 2012, p. 139-149.

[4] Xi Lanxia, Liu Changxu. Summary of Method for Sealing(Leakage) [J]. Initiators \& Pyrotechnics, Vol. 3 (2002), p. 44-48.

[5] Xiao Xiangzheng. Leak Detection Method and Application [M]. China Machine Press, 2010, p. 7-144.

[6] Wu Xiaojian, Yan Rongxin. Leak Detection [M]. China Machine Press, 2005, p. 7-110.

[7] Xue Datong, Xiao Xiangzheng, Li Huijun, et al. Modification of Inside-Out Leak-Testing Technique with Mass Spectrometer Leak-Detector [J]. Chinese Journal of Vacuum Science and Technology, Vol. 38 (2011) No. 1, p. 105-109.

[8] GJB/Z Guideline for the practice of leak detection method for sealed military parts [S].

[9] Zhu Yukun, Zhang Mannian. The Progress of Leak Detection Technology in Chinese HL and European JET Tokamaks [J]. Vacuum And Cryogenics, Vol. 12 (2006) No. 2, p. 63-67.

[10] Bai Guoyun, Liao Xudong, Hu Maozhong. Design of novel-type helium source and its applications [J]. Chinese Journal of Vacuum Science and Technology, Vol. 32 (2014) No. 12, p. 1136-1139. 